Q. J. R. Meteorol. Soc. (2000), 126, pp. 2637-2652

\title{
Propagation Mechanisms for the Madden-Julian Oscillation
}

\author{
By ADRIAN. J. MATTHEWS*
}

Cooperative Research Centre for Southern Hemisphere Meteorology, Monash University, Australia

The Madden-Julian oscillation (MJO) is examined using 20 years of outgoing longwave radiation and NCEP-NCAR reanalysis data. Two mechanisms for the eastward propagation and regeneration of the convective anomalies are suggested.

The first is a local mechanism operating over the warm pool region. At the phase of the MJO with a dipole structure to the convection anomalies, there is enhanced tropical convection over the eastern Indian Ocean and reduced convection over the western Pacific. Over the equatorial western Indian Ocean, the equatorial Rossby wave response to the west of the enhanced convection includes a region of anomalous surface divergence associated with the anomalous surface westerlies and pressure ridge. This tends to suppress ascent in the boundary layer and shuts off the deep convection, eventually leading to a convective anomaly of the opposite sign. Over the Indonesian sector, the equatorial Kelvin wave response to the east of the enhanced convection includes a region of anomalous surface convergence into the anomalous equatorial surface easterlies and pressure trough, which will tend to favour convection in this region. The Indonesian sector is also influenced by an equatorial Rossby wave response (of opposite sign) to the west of the reduced convection over the western Pacific, which also has a region of anomalous surface convergence associated with its anomalous equatorial surface easterlies and pressure trough. Hence, convective anomalies of either sign tend to erode themselves from the west and initiate a convective anomaly of opposite sign via their equatorial Rossby wave response, and expand to the east via their equatorial Kelvin wave response.

The second is a global mechanism involving an anomaly completing a circuit of the equator. Enhanced convection over the tropical western Pacific excites a negative sea level pressure (SLP) anomaly which radiates rapidly eastward as a dry equatorial Kelvin wave at approximately $35 \mathrm{~m} \mathrm{~s}^{-1}$ over the eastern Pacific. It is blocked by the orographic barrier of the Andes and Central America for several days before propagating through the gap at Panama. After rapidly propagating as a dry equatorial Kelvin wave over the Atlantic, the SLP anomaly is delayed further by the East African Highlands before it reaches the Indian Ocean and coincides with the development of enhanced convection at the start of the next MJO cycle.

KEYwORDS: Madden-Julian oscillation Eastward propagation Equatorial Rossby wave Equatorial Kelvin wave Orography

\section{INTRODUCTION}

The Madden-Julian oscillation (MJO) has been extensively studied over the past two decades and is well established as the dominant mode of tropical intraseasonal variability in the atmosphere. It is characterised by eastward-propagating tropical convective anomalies and associated circulation anomalies, with a time period between 30 and 60 days (Knutson and Weickmann 1987; Rui and Wang 1990; Kiladis and Weickmann 1992; Hendon and Salby 1994). However, there is still no universally accepted basic mechanism for the eastward propagation and the regeneration of the convective anomalies over the Indian Ocean at the start of the following cycle.

Many studies have focussed on the role of the eastward-propagating equatorial Kelvin wave. The vertical structure of the MJO is that of a first internal mode, with anomalies in the lower troposphere being out of phase with those in the upper troposphere. A dry, adiabatic wave with such a vertical structure has a phase speed of approximately $40-50 \mathrm{~m} \mathrm{~s}^{-1}$ and would complete a circuit of the globe in approximately 10 days, which is a factor of 4 faster than the observations. If friction, in the form of cumulus momentum transport, is included, the wave can be slowed down to a phase speed closer

* Corresponding author: School of Environmental Sciences, University of East Anglia, Norwich, NR4 7TJ, UK. E-mail: a.j.matthews@uea.ac.uk 
to that of the observations (Chang 1977). Alternatively, the effects of moist convection can also slow the Kelvin wave down, as has been shown in many idealised studies (e.g., Lau and Peng 1987; Emanuel 1987; Neelin et al. 1987; Raymond and Torres 1998). Some of these idealised models can simulate an eastward-propagating tropical mode with a time scale similar to that of the observed MJO. However, atmospheric general circulation models do not tend to simulate the time scale of the MJO well; they tend to produce too short a time period (Slingo et al. 1996).

Recently, coupled ocean-atmosphere interactions have been shown to have a significant effect on the behaviour of the MJO. To the west of the convectively active region, anomalously strong surface winds and ehnhanced evaporation, together with reduced solar insolation act to decrease the sea surface temperature (SST), while to the east, weaker surface winds and enhanced solar insolation increase the SST (Woolnough et al. 2000). The effect of these SST changes in a model is to increase the coherence of organised convection and to slow down the simulated MJO to a phase speed more in accord with observations (Flatau et al. 1997).

Observations indicate that a series of MJOs often occur, one after the other, which suggests that one MJO event may lead to the next. One possibility is that a perturbation propagates eastward and completes a circuit of the equator before initiating the next MJO. This scenario is often implicitly assumed in idealised model studies, where the time scale for the oscillation is calculated as the earth's circumference divided by the modal phase speed. However, the observed MJO convective anomalies are weak or nonexistent over the Western Hemisphere.

There are also periods in the observational record when the MJO is absent, hence at the end of these periods there is clearly a role for spontaneous generation of new MJO events. Bladé and Hartmann (1993) proposed a "discharge-recharge" theory where the time scale of the MJO was set locally, as the time taken for the convective anomaly to grow and decay over the Indian Ocean, followed by a further time over which the convective instability is recharged. They hypothesised that synoptic-scale waves could provide the trigger to initiate the next cycle of MJO convection, and Matthews and Kiladis (1999) observed an enhancement in such high-frequency activity in this region just prior to the onset of MJO convection.

Previous studies of the MJO have used satellite-measured outgoing longwave radiation (OLR) data as a proxy for deep tropical convection and global circulation and pressure data from the operational analyses produced by the national weather centres. Until recently, the length of these data sets has been fairly short, and studies using the analysis data have been hindered by the many ongoing changes made to the operational analysis scheme.

Recently, the National Centers for Environmental Prediction-National Center for Atmospheric Research (NCEP-NCAR) reanalysis project has reanalysed the last 40 years of atmospheric data using a fixed, state-of-the-art analysis scheme (Kalnay et al. 1996). The reanalysis has also benefited from extra atmospheric data that were not input into the original operational analyses. This study examines the MJO using the NCEP-NCAR reanalysis data and the 25 years of OLR data that is now available, with an emphasis on the mechanism for eastward propagation. In particular, it is of interest to examine whether an MJO signal completes a circuit of the equator, and whether one MJO event can trigger or force the next MJO event, or whether individual events arise spontaneously.

\section{DATA}


The OLR data were used as a proxy for deep tropical convection (Arkin and Ardanuy 1989). Deep convective clouds have high, cold cloud tops and are associated with low values of OLR in the Tropics. Similarly, negative OLR anomalies correspond to positive cloudiness or convective anomalies. The OLR data were obtained from National Oceanic and Atmospheric Administration (NOAA) polar-orbiting satellites as a dailymean, gridded, interpolated data set (Liebmann and Smith 1996). The data started on 1 June 1974 and ended on 16 September 1998, with missing data from 16 March to 31 December 1978, inclusive. The NCEP-NCAR reanalysis data were retrieved for the same period as the OLR data. Both data sets were on a $2.5^{\circ}$ longitude $\times 2.5^{\circ}$ latitude grid.

To isolate the MJO signal, the time mean and first three harmonics of the annual cycle were removed from both data sets, which were then passed through a 20-200-day band-pass Lanczos filter with 241 weights. This filter has a much wider bandwidth than filters used in many other studies of the MJO and avoids the problem of successive MJO events being artificially smeared into each other. For example, Fig. 1 shows the effect of the 20-200-day filter and a 241-weight 30-70-day filter on an isolated single sine wave with a period of 48 days, which represents an idealised isolated MJO event with no preceding or following MJO event. The 20-200-day filtered time series is very similar to the original time series, but the 30-70-day filter introduces spurious signals before and after the isolated sine wave. This would have the effect of merging successive MJO events into one another and make it difficult to assign particular anomalies to the beginning of one event or the end of the previous event.

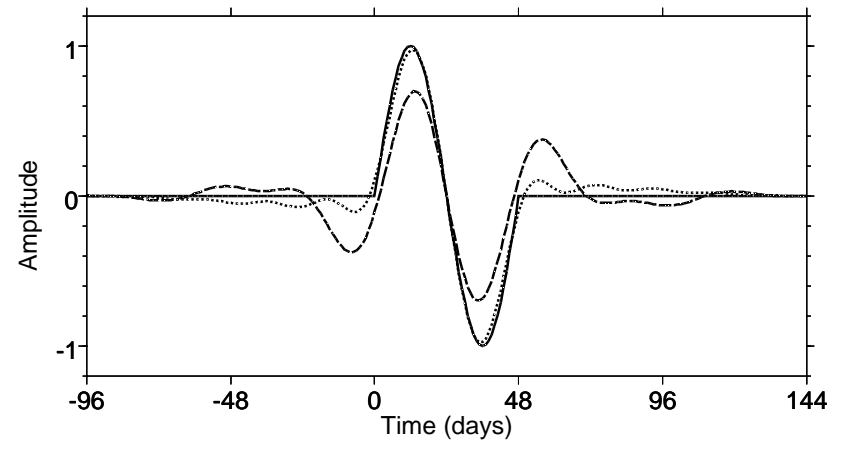

Figure 1. Time series of single sine wave of period 48 days (solid line). The time series passed through the 20-200-day filter (dotted line) and the 30-70-day filter (dashed line).

\section{MJO CYCLE}

\section{(a) EOF analysis}

An empirical orthogonal function (EOF) analysis of the OLR data was used to define the cycle of the MJO. Wilks (1995) gives a comprehensive description of EOF analysis. For computational reasons, the OLR data were first interpolated onto a coarser $5^{\circ}$ longitude $\times 5^{\circ}$ latitude grid. A covariance matrix of the filtered OLR over the Tropics from $25^{\circ} \mathrm{S}$ to $25^{\circ} \mathrm{N}$ was calculated using the 20 years of data for which year-round filtered data was available (1975-76 and 1980-97). The leading two eigenvectors (EOF 1 
and EOF 2) of the covariance matrix accounted for $6.6 \%$ and $5.4 \%$ of the variance*, respectively, and were well separated from the remaining eigenvectors by the criteria of North et al. (1982); EOF 3 accounted for just 1.3\% of the variance and EOFs 3 and above formed a degenerate set of sampling "noise".

The spatial structure of EOF 1 shows the familiar MJO convective dipole, with negative OLR anomalies (enhanced convection) over the Indian Ocean and positive OLR anomalies (reduced convection) over the western Pacific (Fig. 2a). EOF 2 has enhanced convection over Indonesia and reduced convection over the South Pacific convergence zone, South America, Africa and the western Indian Ocean (Fig. 2b), and is spatially in quadrature with EOF 1 . The principal component $(\mathrm{PC})$ time series were calculated by projecting the EOF spatial structures onto the filtered gridded OLR fields at each time, and show the time-varying amplitude of the EOF spatial structures. A two-year subset of the PC time series (1987-1988) is shown in Fig. 2c. PC 1 leads PC 2 by approximately a quarter of a cycle, particularly during a period of strong MJOs from 1 December 1987 to 1 April 1988. Together with the spatial structures of the EOFs, this behaviour of the PC time series describes a pattern of eastward-propagating convective anomalies. The MJO can then be represented by the vector $\mathbf{Z}$ in the two-dimensional phase space defined by the first two PCs.

$$
\mathbf{Z}(t)=[\mathrm{PC} 1(t), \mathrm{PC} 2(t)]
$$

Alternatively, an amplitude $A$ and phase $\alpha$ representation can be used, where $A$ is the length of the vector $\mathbf{Z}$ and $\alpha$ is the angle between the PC1 axis and the vector $\mathbf{Z}$ :

$$
\begin{aligned}
& A(t)=\left[\mathrm{PC}^{2}(t)+\mathrm{PC}^{2}(t)\right]^{1 / 2} \\
& \alpha(t)=\tan ^{-1}[\mathrm{PC} 2(t) / \mathrm{PC} 1(t)]
\end{aligned}
$$

The eastward propagation of the convective anomalies described by PC 1 and PC 2 is associated with an increase in the phase $\alpha$ with time, for example, during the December 1987 to April 1988 period (Fig. 2d). The amplitude of the MJO is also high during this period. The eastward propagation manifests itself as an anticlockwise rotation with time of $\mathbf{Z}(t)$ about the origin in phase space (Fig. 2e).

\section{(b) Regression maps}

The time series $\mathrm{PC} 1(t)$ can be used to construct a regression map for any gridpoint variable $y$ (for example, $1000-\mathrm{hPa}$ geopotential height) for the phase of the MJO corresponding to EOF 1 (i.e., $\alpha=0^{\circ}$ ). At each grid point $i$ a linear regression equation

$$
\hat{y}_{i}=a_{i}+b_{i} \mathrm{PC} 1
$$

is formed where $\hat{y}_{i}$ is the regressed value of the dependent variable $y_{i}$, and $a_{i}$ and $b_{i}$ are constants to be determined for that particular grid point. A map of $\hat{y}$ is then plotted for a fixed value of $\mathrm{PC} 1=2.0$. This choice of the magnitude of the dependent variable $(\mathrm{PC} 1)$ is arbitrary, but corresponds to a typical peak value (Fig. 2c).

A similar regression map of $y$ can be constructed using the PC 2 time series; this will show the pattern of anomalies in $y$ at the phase of the MJO corresponding to EOF 2 (i.e., $\left.\alpha=90^{\circ}\right)$. The anomaly pattern at an intermediate phase $\alpha$ is then a linear combination of the anomaly patterns at $\alpha=0^{\circ}$ and $\alpha=90^{\circ}$ :

$$
\hat{y}(\alpha)=\hat{y}(\mathrm{PC} 1) \cos \alpha+\hat{y}(\mathrm{PC} 2) \sin \alpha
$$

* This relatively small fraction of variance is due to the wide band width of the 20-200-day filter. If a narrower 30-70-day filter was used, the total variance accounted for by the first two EOFs increased to $24.3 \%$. 
(a) EOF1

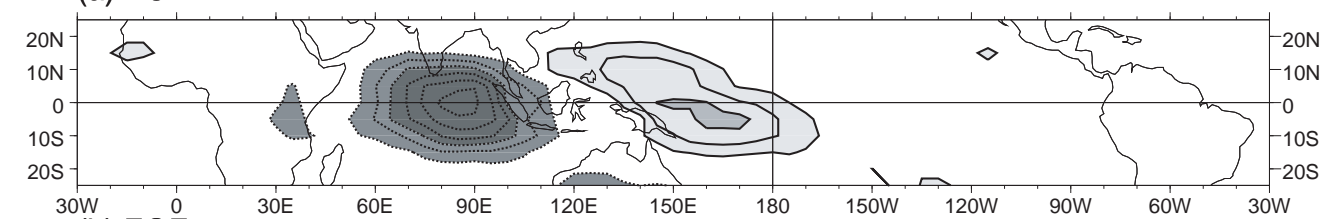

(b) EOF2

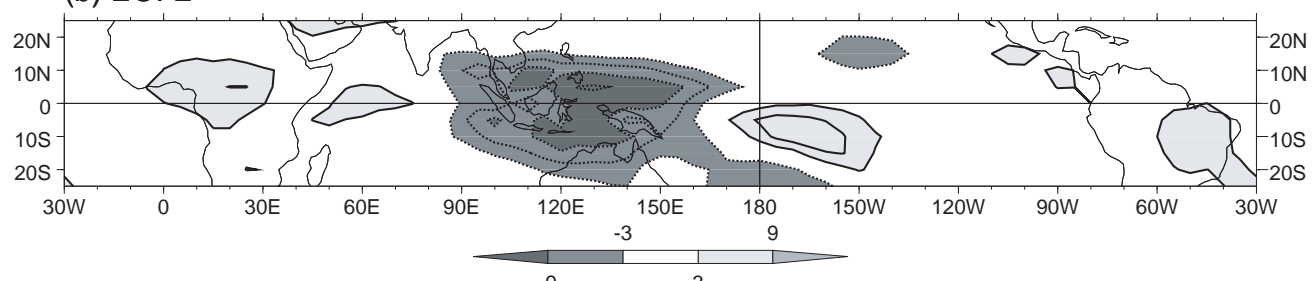

(c) PC Time Series: $1987-1988$

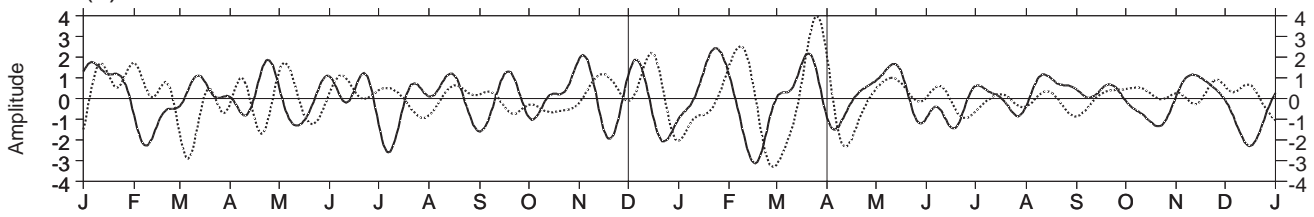

(d) Z: Phase, Amplitude (41-day running mean): 1987 - 1988

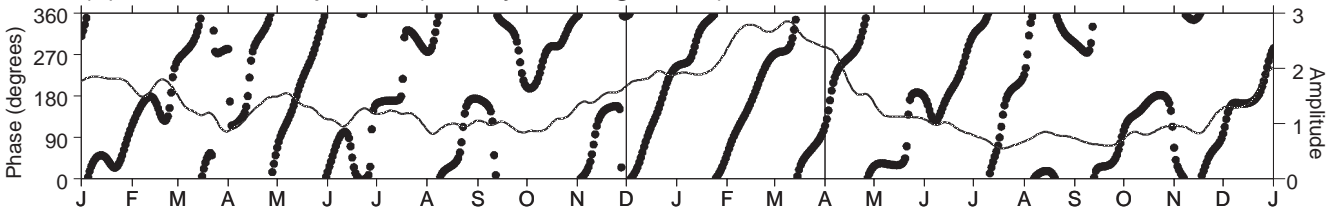

(e) Z: 1 Dec 1987 - 1 Apr 1988

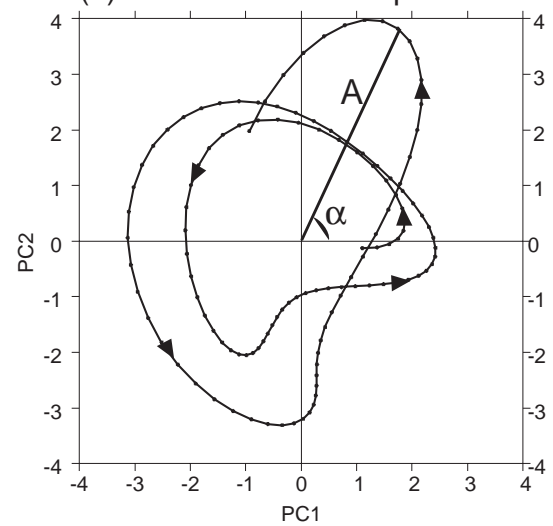

Figure 2. Empirical orthogonal function analysis of 20-200-day filtered OLR. (a) EOF 1, (b) EOF 2; contour interval is $3 \mathrm{~W} \mathrm{~m} \mathrm{~m}^{-2}$; the zero contour is omitted; shading is shown by the legend. (c) PC 1 (solid line) and PC 2 (dotted line) from 1 January 1987 to 31 December 1988. (d) Phase $\alpha$ (dots; scale on left-hand axis) and 41-day running mean of amplitude $A$ (solid line; scale on right-hand axis) of $\mathbf{Z}$ from 1 January 1987 to 31 December 1988. (e) Z plotted from 1 December 1987 to 1 April 1988. 
Because of the broad-band nature of the MJO (the period of any individual MJO can vary by a factor of 2, between 30 and 60 days), there is an advantage to using this phase representation rather than constructing time-lagged regression or composite maps with respect to PC 1 or some other measure of the MJO at a particular phase (e.g., Knutson and Weickmann 1987; Hendon and Salby 1994). With the time-lagged method, MJOs with different time scales can destructively interfere with each other at the longer time lags, and the strongest signal is obtained at zero lag. This assigns a special "significance" to the phases of the MJO corresponding to \pm EOFs 1 and 2, while information can be lost at intermediate phases. This is not a problem when the phase representation is used, as all phases of the MJO are treated equally. A disadvantage of the phase representation is that the explicit time dependence is lost. However, a nominal time can be assigned to each phase; if the total cycle is assumed to be 48 days long, then phases that are, say, $1 / 16$ cycle or $22.5^{\circ}$ apart are nominally 3 days apart.

\section{Results}

\section{(a) Tropical convection}

The MJO cycle for OLR is shown at phase intervals of $22.5^{\circ}$ (nominally 3 days apart) in Fig. 3. The $\alpha=0^{\circ}$ phase in Fig. 3a has essentially the same pattern as +EOF 1 in Fig. 2a, but scaled by a factor of 2 . Similarly, the $\alpha=90^{\circ}, 180^{\circ}$ and $270^{\circ}$ phases have the same patterns as +EOF 2, -EOF 1 and -EOF 2, respectively. The intermediate phases allow the development of the convection anomalies to be examined in more detail. The OLR anomalies in the latter half of the cycle (right-hand panels in Fig. 3) have identical patterns, but with opposite sign, to those of their corresponding phases $\left(180^{\circ}\right.$ earlier $)$ in the first half of the cycle (left-hand panels in Fig. 3).

At the start of the MJO cycle $\left(\alpha=0^{\circ}\right.$ phase; Fig. 3a), there is enhanced convection over the Indian Ocean. The western edge of this enhanced convection subsequently disappears most rapidly at the equator, such that by phase $\alpha=67.5^{\circ}$ (Fig. 3d) a "bite" appears to have been taken out of it at $0^{\circ}, 70^{\circ} \mathrm{E}$. A small region of reduced convection at $0^{\circ}, 55^{\circ} \mathrm{E}$ has now appeared, which eventually grows to form the large region of reduced convection over the Indian Ocean half way through the MJO cycle $\left(\alpha=180^{\circ}\right.$ phase; Fig. 3i).

At the start of the MJO cycle $\left(\alpha=0^{\circ}\right.$ phase $)$ there is also a region of reduced convection over the western Pacific, which reached its peak toward the end of the previous cycle $\left(\alpha=315^{\circ}\right.$ phase; Fig. 3o). This reduced convection also disappears most rapidly on, or slightly to the north of, the equator $\left(\alpha=22.5^{\circ}\right.$ phase; Fig. $\left.3 \mathrm{~b}\right)$ and is replaced by a tongue of enhanced convection extending eastward along $5^{\circ} \mathrm{N}$ from the main region of enhanced convection over the Indian Ocean $\left(\alpha=45^{\circ}\right.$ phase; Fig. 3c).

\section{(b) Warm pool dynamics}

The development of the equatorial convective anomalies over the warm pool is now interpreted in terms of equatorial wave dynamics. The near-surface (1000-hPa) geopotential height and wind vector anomalies during the $\alpha=0^{\circ}$ phase are shown in Fig. 4a. OLR contours are drawn at $\pm 5 \mathrm{~W} \mathrm{~m}^{-2}$ to show the outline of the convective anomalies. The enhanced convection over the Indian Ocean is colocated with a negative equatorial 1000-hPa geopotential height anomaly, which extends poleward and westward into both hemispheres. The 1000-hPa wind vectors show anomalous cyclonic flow around these 


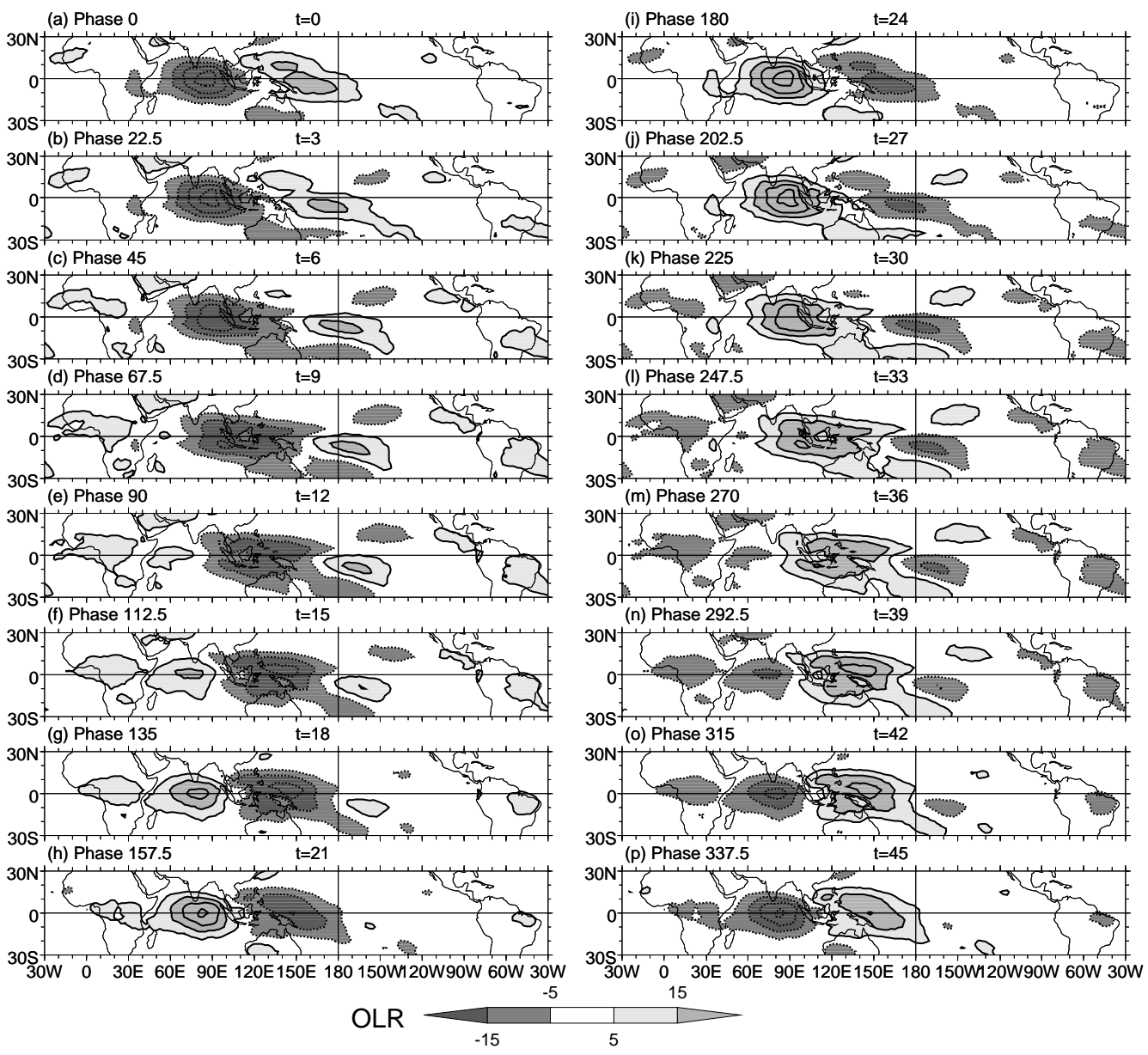

Figure 3. Regression maps of OLR for every $22.5^{\circ}$ of phase $\alpha$ of the MJO cycle, scaled to a deviation of $\mathrm{PC} 1 / 2=2.0$. Contour interval is $10 \mathrm{~W} \mathrm{~m}^{-2}$; the first positive contour is at $5 \mathrm{~W} \mathrm{~m}^{-2}$; negative contours are dotted; shading is shown by the legend. The approximate time $t$ in days is also shown.

negative geopotential height or low-pressure centers (the terms will be used interchangeably), with down-gradient westerly anomalies along the equator over the western Indian Ocean. These anomalies are consistent with an equatorial Rossby wave response to the diabatic heating associated with the enhanced convection (Gill 1980).

The 1000-hPa divergence field (Fig. 4b) shows anomalous equatorial convergence at the center of the enhanced convection $\left(0^{\circ}, 85^{\circ} \mathrm{E}\right)$, consistent with the Gill model of tropical heating. The anomalous surface convergence at the centers of the two offequatorial cyclonic anomalies can be interpreted as frictional inflow into the low-pressure anomalies. However, there is anomalous surface divergence on the equator at the western edge of the enhanced convection $\left(40^{\circ}-60^{\circ} \mathrm{E}\right)$. This divergence is entirely due to the decrease in strength of the westerly anomalies with distance westward from the enhanced convection (the $\partial u / \partial x$ component; the $\partial v / \partial y$ component is weakly negative), possibly due to surface friction. This anomalous surface divergence over the equatorial western Indian Ocean will tend to suppress ascent in the boundary layer and act to reduce the enhanced convection that is present over the region at this phase of the MJO. Such an interpretation is consistent with the disappearance of enhanced convection over the 
(a)

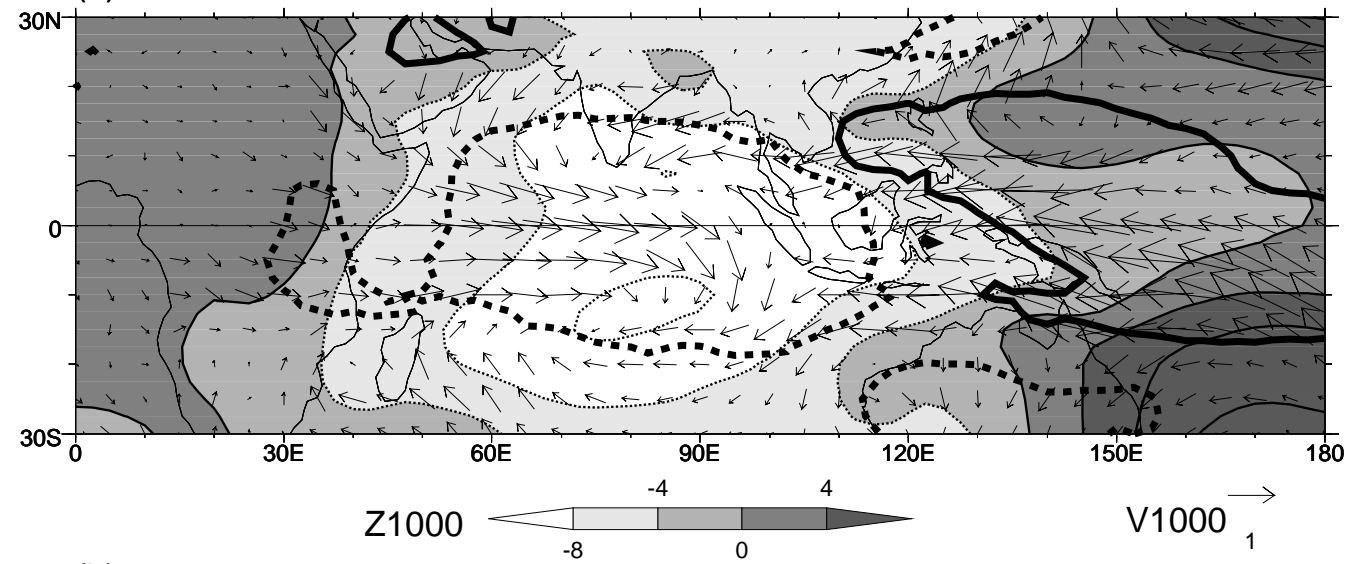

(b)

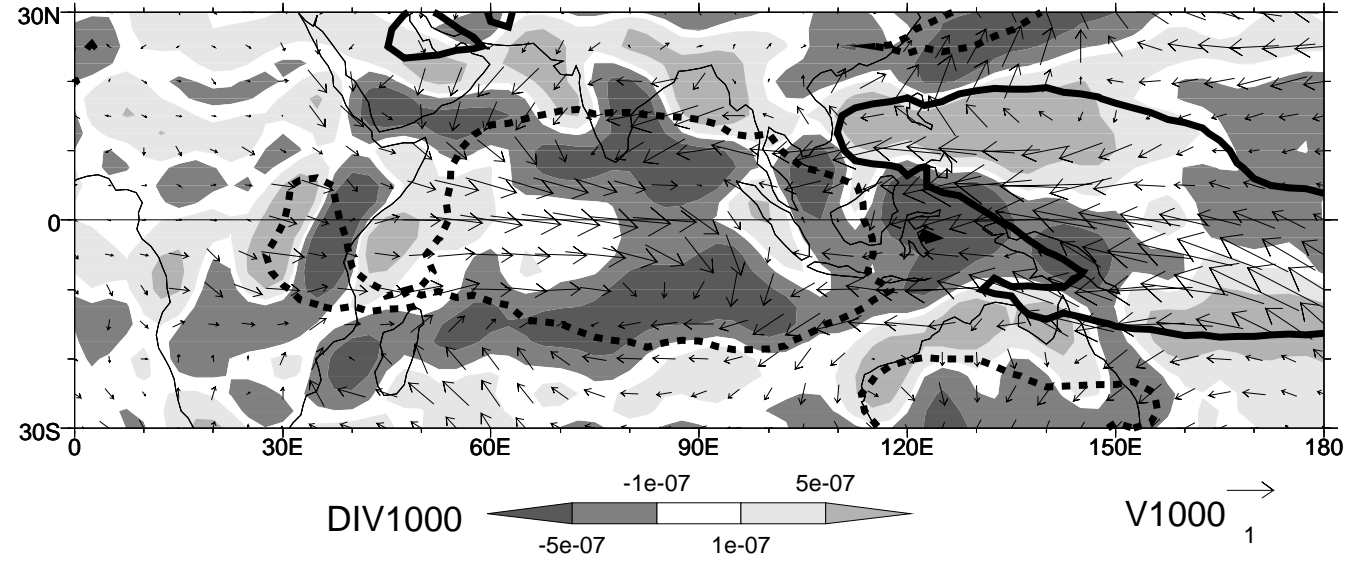

Figure 4. As in Fig. 3 but at the $\alpha=0^{\circ}$ phase only for (a) OLR and 1000-hPa geopotential height and wind vectors. OLR is contoured at $-5 \mathrm{~W} \mathrm{~m}^{-2}$ (thick dashed line) and $+5 \mathrm{~W} \mathrm{~m}^{-2}$ (thick solid line). Geopotential height contour interval is $4 \mathrm{~m}$; see legend for shading. The reference wind vector is $1 \mathrm{~m} \mathrm{~s}^{-1}$.

(b) as in (a) except for 1000-hPa divergence; see legend for shading.

equatorial western Indian Ocean in the subsequent phases of the MJO and their eventual replacement by a negative convective anomaly (Fig. 3b-d), as discussed above.

The situation is more complex to the east of the enhanced convection. A tongue of anomalous low pressure extends eastward from the enhanced convection over the Indian Ocean into the western Pacific along and to the north of the equator (Fig. 4a). Together with the associated easterly equatorial wind anomalies, this is consistent with an equatorial Kelvin wave response to the enhanced convection. However, there also appears to be an equatorial Rossby wave of opposite sign, arising as a response to the reduced convection over the western Pacific, with anomalous off-equatorial high pressure and anticyclonic anomalies and equatorial easterly flow down the pressure gradient. Therefore, the equatorial low pressure and easterly wind anomalies over the western Pacific can be attributed to both an equatorial Kelvin wave response to the enhanced convection over the Indian Ocean and an equatorial Rossby wave response (of opposite sign) to the reduced convection over the western Pacific.

The 1000-hPa divergence anomalies over the Indonesian-western Pacific region (Fig. 4b) 
follow a similar pattern to those over the Indian Ocean, but with opposite sign. There is anomalous divergence at the center of the off-equatorial anticyclones and anomalous convergence within the equatorial easterlies. The anomalous equatorial convergence is due to both the $\partial u / \partial x$ and $\partial v / \partial y$ components and can be attributed to a decrease in the strength of the equatorial easterly anomalies with increasing westward distance from the reduced convection (the equatorial Rossby wave response) and frictional inflow into the anomalous equatorial pressure trough, respectively.

The anomalous equatorial surface convergence over the Indonesian-western Pacific sector will tend to be associated with anomalous ascent in the boundary layer and destabilisation of the atmosphere, leading to the disappearance of the reduced convection and the eastward expansion of the enhanced convection, as discussed above.

Therefore, the convective anomalies tend to destroy themselves from the west via their equatorial Rossby wave response and expand to the east via their equatorial Kelvin wave response. As the analysis is linear, these arguments can be applied to the second half of the MJO cycle if the sign is reversed. In particular, a small region of enhanced convection over the equatorial western Indian Ocean at $0^{\circ}, 55^{\circ} \mathrm{E}$ appears during the $\alpha=247.5^{\circ}$ phase (Fig. 31) and grows to become the main region of enhanced convection in the next cycle of the MJO ( $\alpha=337.5^{\circ}$ and $360^{\circ}$ or $0^{\circ}$ phases; Fig. $\left.3 \mathrm{p}, \mathrm{a}\right)$. The small region of convection over the equatorial western Indian Ocean at the $\alpha=247.5^{\circ}$ phase can be attributed to the region of anomalous $1000-\mathrm{hPa}$ convergence that preceded it during the $\alpha=180^{\circ}$ phase (Fig. 4 ; reverse sign of anomalies). This anomalous surface convergence was part of the equatorial Rossby wave response to the reduced convection over the Indian Ocean at that phase. This equatorial Rossby wave mechanism is essentially a regional mechanism, in that one cycle of the MJO can trigger the next cycle by dynamics that are confined to the warm pool; it is not necessary for a signal to complete a circuit of the equator.

\section{(c) Equatorial Kelvin waves and orography}

In this section an alternative mechanism is examined that does involve a dynamical signal completing a circuit of the globe. The MJO cycle of sea level pressure (SLP) over the whole tropical domain is shown in Fig. 5 , together with the outline of the OLR anomalies. At the $\alpha=0^{\circ}$ phase (Fig. 5a) the enhanced convection (negative OLR) and negative SLP anomalies are colocated over the Indian Ocean near $90^{\circ} \mathrm{W}$; the SLP anomalies have a similar equatorial Rossby/Kelvin wave structure to the $1000-\mathrm{hPa}$ geopotential height anomalies in Fig. 4a.

The enhanced equatorial convection then propagates slowly eastward over the warm pool region at approximately $4 \mathrm{~m} \mathrm{~s}^{-1}$. This is shown by a straight dotted line segment on an equatorial Hovmöller diagram (Fig. 6). The negative SLP anomaly propagates eastward at a faster speed of $8 \mathrm{~m} \mathrm{~s}^{-1}$ over the warm pool, and then at approximately $35 \mathrm{~m} \mathrm{~s}^{-1}$ over the Pacific (straight solid line segments in Fig. 6) as an equatorial Kelvin wave until it reaches South America where it is blocked by the Andes mountain range $\left(\alpha=45^{\circ}\right.$ phase; Fig. 5c). The Andes and the mountain ranges of Central America form an almost unbroken barrier across the tropics (Fig. 7) and the SLP anomaly propagates northward and southward as a trapped wave against this orographic barrier. However, there is a gap at Panama near $10^{\circ} \mathrm{N}$. By the $\alpha=112.5^{\circ}$ phase (Fig. 5f) the SLP anomaly has propagated through the Panama gap; it then propagates rapidly eastward across the Atlantic at approximately $35 \mathrm{~m} \mathrm{~s}^{-1}$ as an equatorial Kelvin wave until it is blocked for a second time, by the East African Highlands $\left(\alpha=180^{\circ}\right.$ phase; Fig. 5i). After a delay of about $90^{\circ}$ of phase, or approximately 12 days, the negative SLP anomaly propagates eastward into the Indian Ocean and completes a circuit of the equator. 


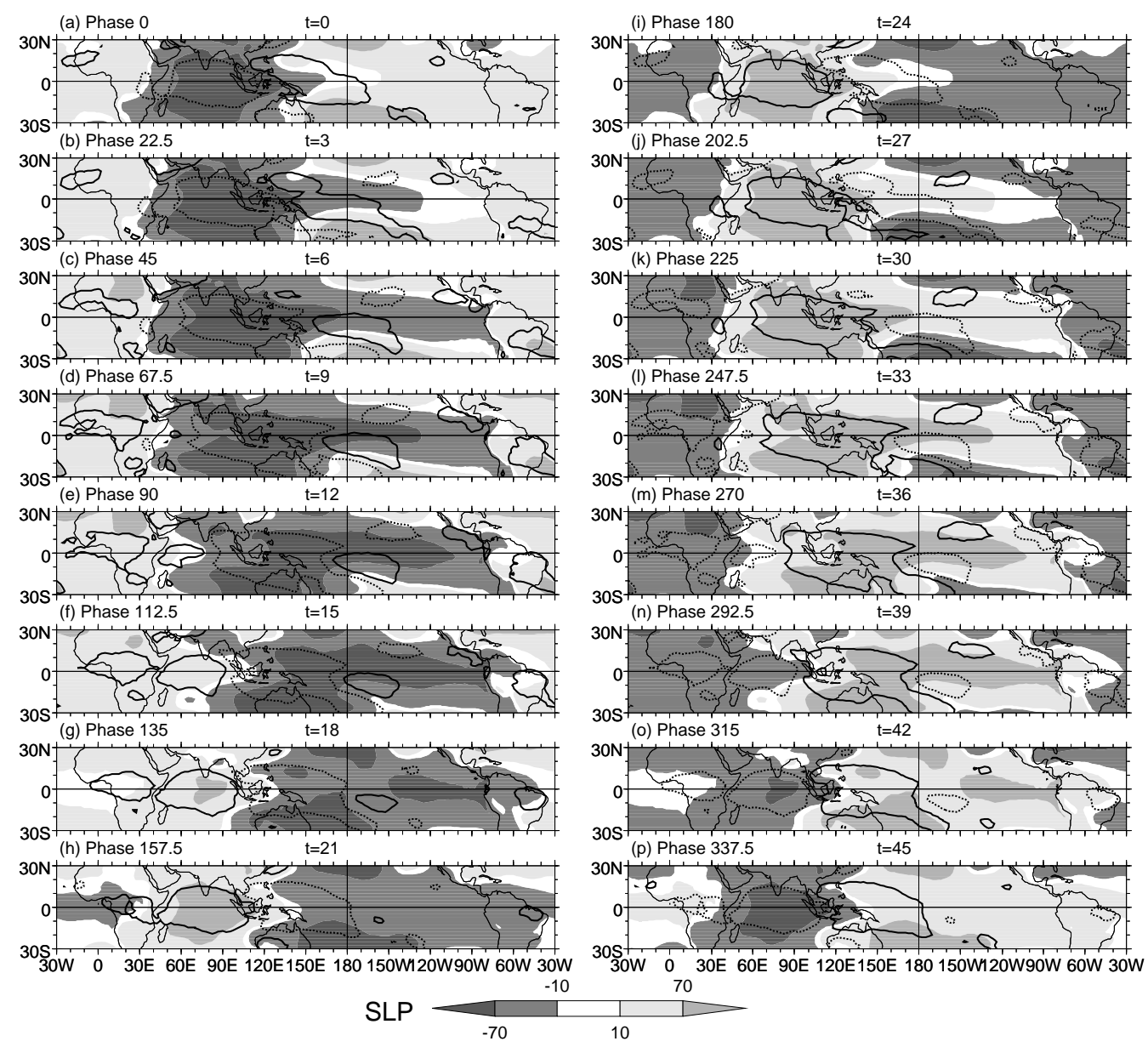

Figure 5. As in Fig. 3 but for SLP and OLR. SLP is shaded at $\pm 10,70 \mathrm{~Pa}$; see legend. OLR is contoured at $-5 \mathrm{~W} \mathrm{~m}^{-2}$ (dashed line) and $+5 \mathrm{~W} \mathrm{~m}^{-2}$ (solid line).

The vertical structure of the equatorial Kelvin wave is shown by the latitude-pressure cross-sections of geopotential height anomalies in Fig. 8. During the $\alpha=67.5^{\circ}$ phase the negative equatorial SLP anomaly is propagating across the eastern Pacific (Fig. 5d). The equatorial geopotential height anomalies at this phase at $120^{\circ} \mathrm{W}$ (Fig. 8a) are negative at the surface, change sign in the middle troposphere and are positive in the upper troposphere, consistent with the first internal mode Kelvin wave over the Pacific reported by Milliff and Madden (1996) and a fast Kelvin wave structure in satellite-measured (Microwave Sounding Unit) temperature (Bantzer and Wallace 1996). There are also large subtropical anomalies that do not appear to be associated with the Kelvin wave. It appears that these form part of a wave train propagating meridionally across the equator over the eastern Pacific. Eastward propagation of upper tropospheric geopotential height anomalies can be seen but they are disrupted by this wave train. An idealised modelling study should help to resolve the effect of the Andes mountain range on the vertical structure of the Kelvin wave. The vertical structure over the Atlantic at $30^{\circ} \mathrm{W}$ during the $\alpha=157.5^{\circ}$ phase shows a similar pattern (Fig. 8b), with out of phase anomalies between the equatorial upper and lower troposphere and large subtropical anomalies.

There is a coherent relationship between the tropical convective anomalies over South 


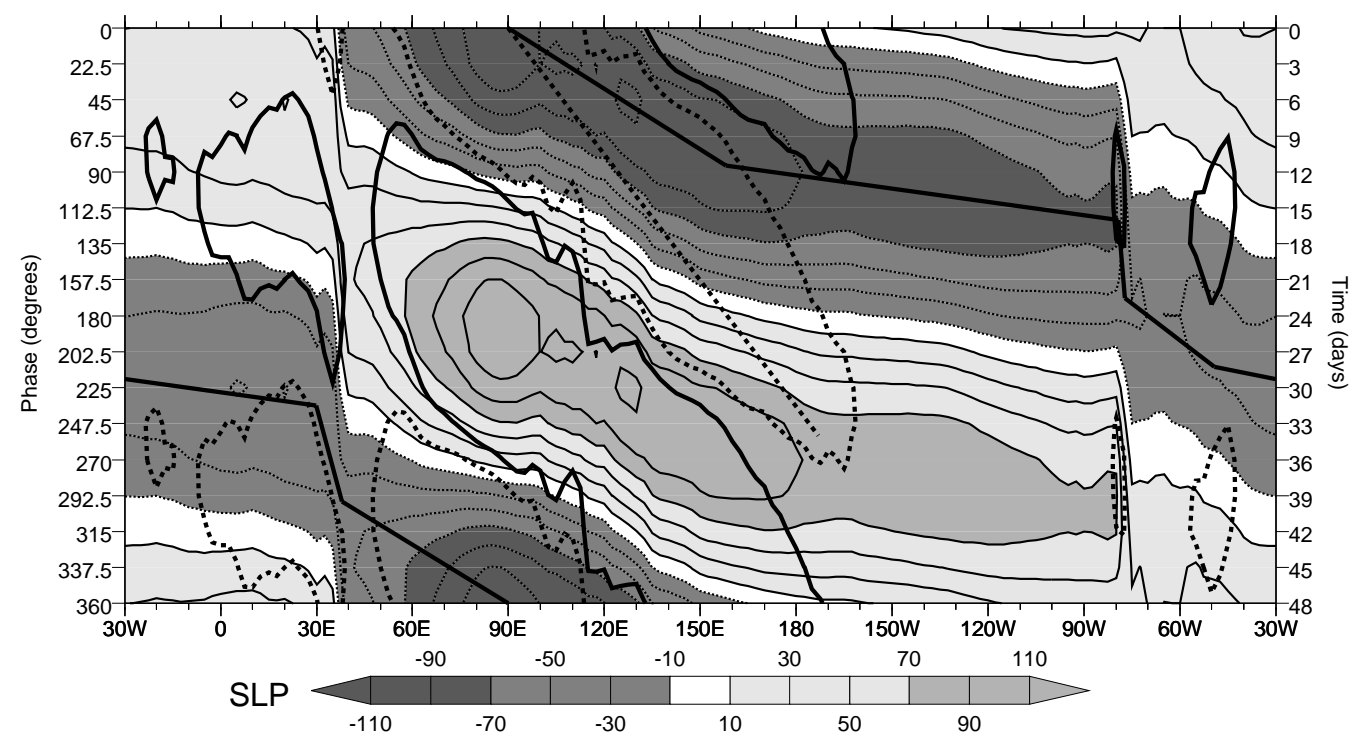

Figure 6. Hovmöller diagram of SLP and OLR at the equator. SLP contour interval is $20 \mathrm{~Pa}$; first positive contour is at $10 \mathrm{~Pa}$; negative contours are dotted; shading is as in Fig. 5 (see legend). OLR is contoured at $-5 \mathrm{~W} \mathrm{~m}^{-2}$ (dashed line) and $+5 \mathrm{~W} \mathrm{~m}^{-2}$ (solid line). The straight line segments indicate phase speeds of the anomalies; see text for details.

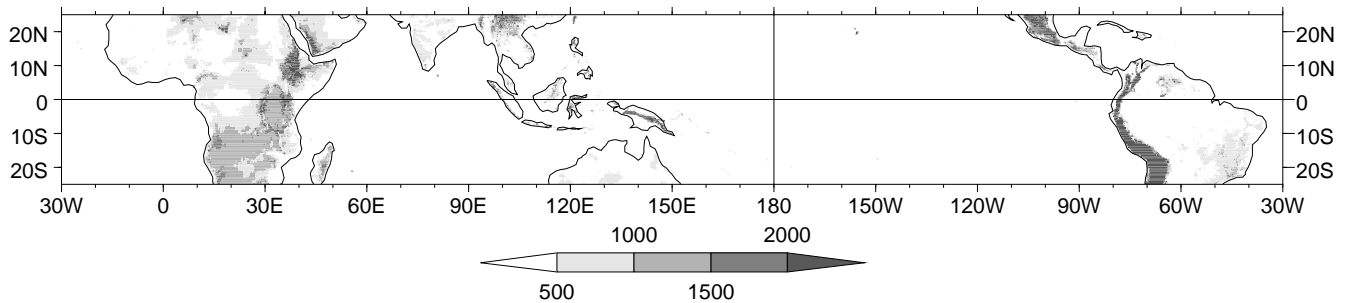

Figure 7. Surface orography. Shading interval is $500 \mathrm{~m}$.

America and Africa and the passage of the SLP anomaly. This can be seen in the regression maps of Fig. 5 and the equatorial Hovmöller diagram (Fig. 6) where the negative SLP anomaly leads the enhanced convection by a quarter of a cycle near $50^{\circ} \mathrm{W}$ and $15^{\circ}$ E. Such a phase relationship points toward the negative SLP anomaly forcing the MJOrelated convection over these regions. The amplitude of the convective anomalies over South America and Africa is small (Fig. 3) and the dynamical response to this convection appears to be weak.

The appearance of the small region of enhanced convection over the equatorial western Indian Ocean during the $\alpha=247.5^{\circ}$ phase (Figs. 31 and 5l) that signifies the beginning of the next cycle of MJO convection is reexamined. In the previous section this was attributed to the equatorial Rossby wave response to the large region of reduced convection over the Indian Ocean at the $\alpha=180^{\circ}$ phase. Over the western Indian Ocean, this equatorial Rossby wave has a local equatorial SLP minimum between two off-equatorial SLP maxima (Fig. 5i, or Fig. 4a with the sign reversed). The anomalous surface easterly winds flow down the pressure gradient along the equator (Fig. 4a with the sign reversed) and the anomalous surface convergence associated with these easterlies was hypothesised to lead to the next cycle of MJO convection. 
(a)

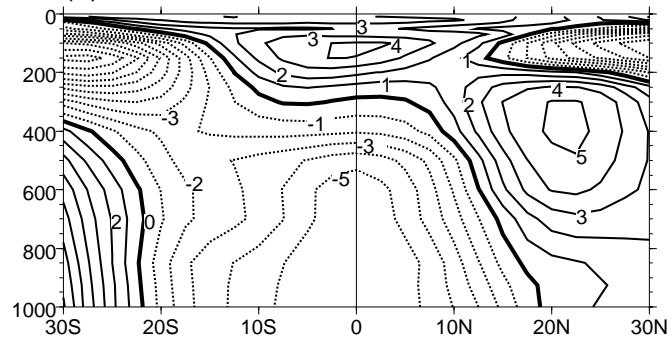

(b)

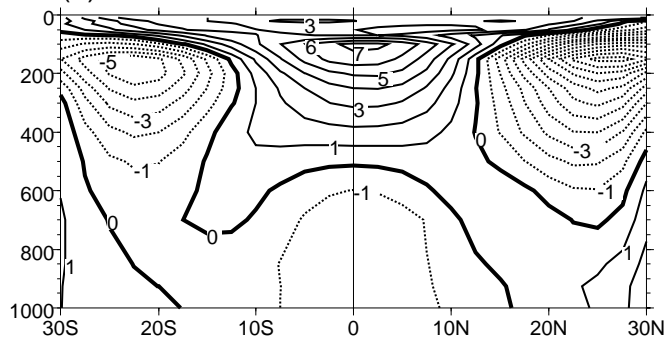

Figure 8. As in Fig. 3 but for latitude-pressure sections of geopotential height anomalies at the (a) $\alpha=67.5^{\circ}$ phase at $120^{\circ} \mathrm{W}$, (b) $\alpha=157.5^{\circ}$ phase at $30^{\circ} \mathrm{W}$. Contour interval is $1 \mathrm{~m}$; negative contours are dotted and the zero contour is thickened.

However, the equatorial SLP minimum over the western Indian Ocean may also be attributable to the eastward-propagating Kelvin wave, as at $60^{\circ} \mathrm{E}$ the equatorial SLP anomaly is propagating eastward with time at the $\alpha=247.5^{\circ}$ phase (Fig. 6). Hence the Kelvin wave SLP anomaly may reinforce the local equatorial SLP minimum due to the equatorial Rossby wave and help create the conditions favourable for the next cycle of MJO convection.

\section{Discussion}

The MJO cycle described here has suggested two mechanisms for the eastward propagation of the convective anomalies and the initiation of the next MJO cycle over the Indian Ocean. In the first mechanism, surface frictional divergence and convergence associated with the dynamical response to convection leads to convective anomalies eroding themselves from the west via their equatorial Rossby wave response and expanding to the east via their equatorial Kelvin wave response. This mechanism is hypothesised to act only over the warm pool, where the MJO can be considered as a perturbation to a basic state of time-mean convection, hence the mechanism is linear and can be applied to convective anomalies of either sign. If the warm pool region is bounded by Africa to the west and the cooler sea surface temperatures of the eastern Pacific to the east, then the schematic in Fig. 9 describes how the convective anomalies propagate eastward and regenerate to the west. Therefore, successive cycles of the MJO can be generated locally within the warm pool region. Hendon and Salby (1994) also noted that anomalous MJO convection was preceded by anomalous surface convergence, which they attributed to frictional Kelvin wave-CISK (Conditional Instability of the Second Kind). However, the surface convergence in their study was due to the $\partial v / \partial y$ component, not the $\partial u / \partial x$ component as was found here. This may be related to the more selective spatial and temporal filtering they used.

The second mechanism, where the next cycle of the MJO is initiated by a Kelvin wave completing a circuit of the equator, has received much attention in the past. As described in Section 1, the effects of moisture and friction have been used to slow the dry Kelvin wave down to a phase speed in line with observations. The blocking and delay of the surface Kelvin wave by the orographic barriers of the Andes-Central America and the East African Highlands, as described here, may be a further mechanism that can be invoked to slow the dry wave down to match the observations. The meridional propagation of the SLP anomaly as a trapped wave against the Andes leads to a pressure torque across the mountain range which is a significant part of the angular momentum 


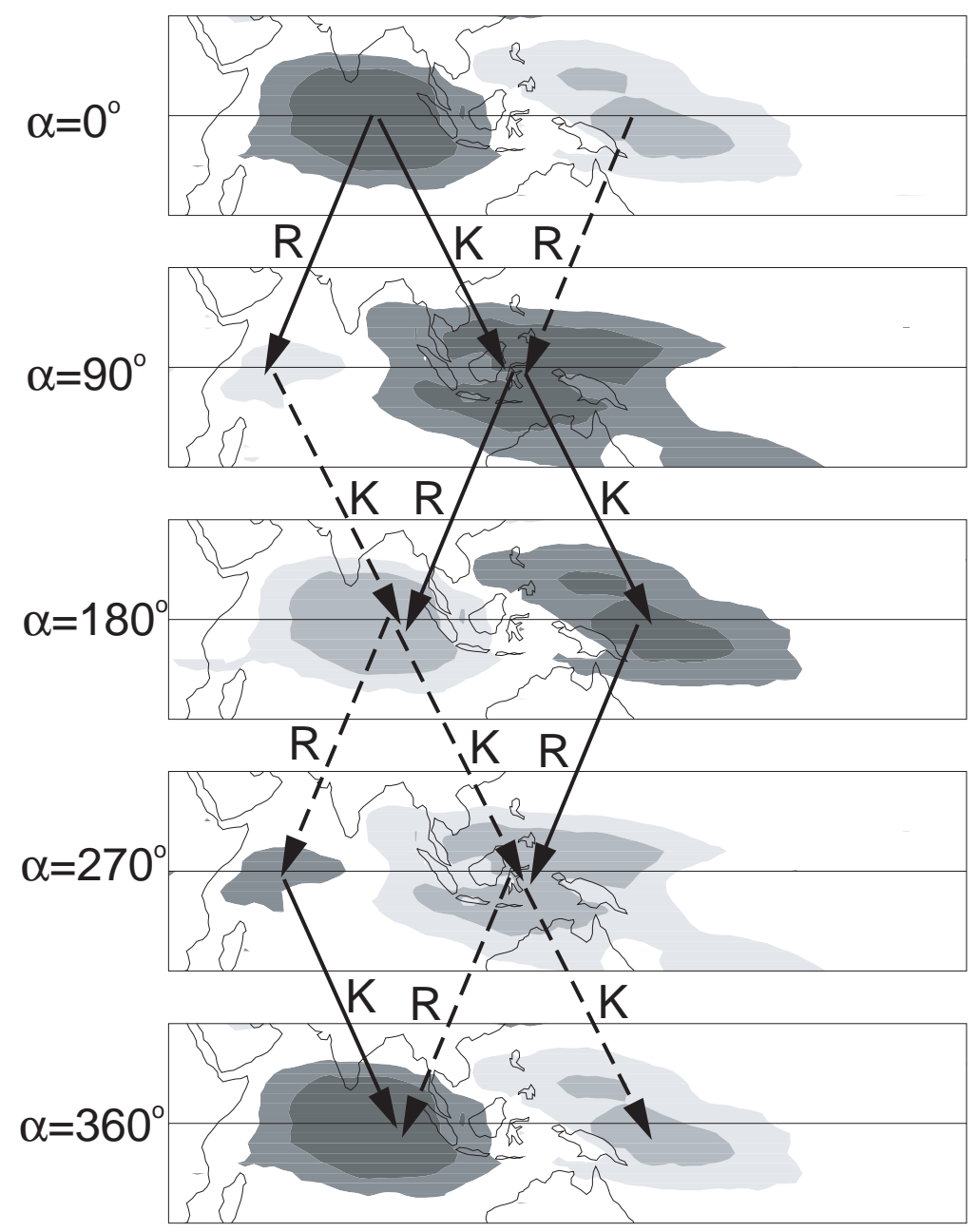

Figure 9. Schematic of the warm pool equatorial wave-surface friction mechanism. Selected regions of enhanced convection are shaded darkly and reduced convection are shaded lightly. The arrows show propagation of equatorial Rossby $(\mathrm{R})$ and Kelvin $(\mathrm{K})$ waves leading to new convective anomalies.

budget of the MJO (Weickmann et al. 1997). This behaviour has also been noted in a general circulation model analog of the MJO (Matthews et al. 1999).

It appears likely that several mechanisms are important in determining the behaviour of the MJO. The two mechanisms proposed here are certainly compatible with those described in section 1 such as the ocean-atmosphere coupling, in that they act to enhance convection to the east and shut it off to the west. The relative magnitudes of these different mechanisms may also vary from one MJO event to another. Both the equatorial Rossby wave-surface friction and the equatorial Kelvin wave-orography mechanisms are currently the subject of a numerical model study, to be reported on later.

\section{ACKNOWLEDGEMENT}

The author thanks David Karoly, Jorgen Frederiksen, Rol Madden and Jun-Ichi Yano for helpful discussions. The comments of an anonymous reviewer helped to improve the 
manuscript. The OLR and NCEP-NCAR reanalysis data were provided through the NOAA Climate Diagnostics Center (http://www.cdc.noaa.gov). The surface orography data were provided by Ken Sperber. This research was supported through the Australian Government Cooperative Research Centres Program.

\section{REFERENCES}

Arkin, P. A. and Ardanuy, P. E. 1989

Bantzer, C. H. and

Wallace, J. M.

Bladé, I. and Hartmann, D. L.

Chang, C. -P.

Emanuel, K. A.

Flatau, M., Flatau, P. J.,

Phoebus, P. and Niiler, N. N.

Gill, A. E.

Hendon, H. H. and Salby, M. L.

Kalnay, E., Kanamitsu, M., Kistler, R., Collins, W., Deaven, D., Gandin, L., Iredell, M., Saha, S., White, G., Woollen, J., Zhu, Y., Chelliah, M., Ebisuzaki, W., Higgins, W., Janowiak, J., Mo, K. C., Ropelewski, C., Wang, J., Leetma, A., Reynolds, R., Jenne, R. and Joseph, D.

Kiladis, G. N. and

Weickmann, K. M.

Knutson, T. R. and

Weickmann, K. M.

Lau, K. -M. and Peng, L.

Liebmann, B. and Smith, C. A.

Matthews, A. J. and

Kiladis, G. N.

Matthews, A. J., Slingo, J. M, Hoskins, B. J. and Inness, P. M. Milliff, R. F. and Madden, R. A.

Neelin, J. D., Held, I. M. and Cook, K. H.

North, G. R., Bell, T. L.

Cahalan, R. F. and

Moeng, F. J.

Raymond, D. J. and

Torres, D. J.
Estimating climatic-scale precipitation from space: A review. J. Climate, 2, 1229-1238

1996 Intraseasonal variability in tropical mean temperature and precipitation and their relation to the tropical 40-50 day oscillation. J. Atmos. Sci., 53, 3032-3045

1993 Tropical intraseasonal oscillations in a simple nonlinear model. J. Atmos. Sci., 50, 2922-2939

1977 Viscous internal gravity waves and low-frequency oscillations in the tropics. J. Atmos. Sci., 34, 901-910

1987 An air-sea interaction model of intraseasonal oscillations in the tropics. J. Atmos. Sci., 44, 2324-2340

1997 The feedback between equatorial convection and local radiative and evaporative processes: The implications for intraseasonal oscillations. J. Atmos. Sci., 54, 2373-2386

1980 Some simple solutions for heat-induced tropical circulation. Q. J. R. Meteorol. Soc., 106, 447-462

1994 The life cycle of the Madden-Julian oscillation. J. Atmos. Sci., 51, 2225-2237

1996 The NCEP/NCAR 40-year reanalysis project. Bull. Am. Meteorol. Soc., 77, 437-471

1992 Circulation anomalies associated with tropical convection during northern winter. Mon. Weather Rev., 120, 19001923

1987 30-60 day atmospheric oscillations: composite life cycles of convection and circulation anomalies. Mon. Weather Rev., 115, 1407-1436

1987 Origin of low-frequency (intraseasonal) oscillations in the tropical atmosphere. Part I: Basic theory. J. Atmos. Sci., 44, 950-972

1996 Description of a complete (interpolated) OLR dataset. Bull. Am. Meteorol. Soc., 77, 1275-1277

1999 The tropical-extratropical interaction between highfrequency transients and the Madden-Julian oscillation. Mon. Wea. Rev., 127, 661-677

1999 Fast and slow Kelvin waves in the Madden-Julian oscillation of a GCM. Q. J. R. Meteorol. Soc., 125, 1473-1498

1996 The existence and vertical structure of fast, eastwardmoving disturbances in the equatorial troposphere. $J$. Atmos. Sci., 53, 586-597

1987 Evaporation-wind feedback and low frequency variability in the tropical atmosphere. J. Atmos. Sci., 44, 2341-2348

1982 Sampling errors in the estimation of empirical orthogonal functions. Mon. Wea. Rev., 110,699-706

1998 Fundamental moist modes of the equatorial troposphere. J. Atmos. Sci., 55, 1771-1790 
Rui, H. and Wang, B.

Slingo, J. M., Sperber, K. R., Boyle, J. S., Ceron, J. -P.,

Dix, M., Dugas, B.,

Ebisuzaki, W., Fyfe, J.,

Gregory, D., Gueremy, J.- F.,

Hack, J., Harzallah, A.,

Inness, P., Kitoh, A.,

Lau, W. K. -M., McAvaney, B.,

Madden, R., Matthews, A.,

Palmer, T. N., Park, C. -K.

Randall, D. and Renno, N.

Weickmann, K. M.,

Kiladis, G. N. and

Sardeshmukh, P. D.

Wilks, D. S.

Woolnough, S. J., Slingo, J. M. and Hoskins, B. J.
1990 Development characteristics and dynamic structure of tropical intraseasonal convective anomalies. J. Atmos. Sci., 47, 357-379

1996 Intraseasonal oscillations in 15 atmospheric general circulation models: results from an AMIP diagnostic subproject. Climate Dynamics, 12, 325-358

1997 The dynamics of intraseasonal atmospheric angular momentum oscillations. J. Atmos. Sci., 54, 1445-1461

1995 Statistical methods in the atmospheric sciences. Academic Press, $467 \mathrm{pp}$.

2000

The relationship between convection and sea surface temperature on intraseasonal timescales. J. Climate, 13, 20862104 